(C) [2005] IEEE. Reprinted, with permission, from [Chindurza, David G Dorrell and C. Cossar, Assessing the core losses in switched reluctance machines, Magnetics, IEEE Transactions on, Volume: 41 , Issue: 10 Oct. 2005]. This material is posted here with permission of the IEEE. Such ermission of the IEEE does not in any way imply IEEE endorsement of any of the University of Technology, Sydney's products or services. Internal or personal use of this material is permitted. However, permission to reprint/republish this material for advertising or promotional purposes or for creating new collective works for resale or redistribution must be obtained from the IEEE by writing to pubspermissions@ieee.org. By choosing to view this document, you agree to all provisions of the copyright laws protecting it 


\title{
Assessing the Core Losses in Switched Reluctance Machines
}

\author{
I. Chindurza, David G Dorrell, Member IEEE and C. Cossar
}

\begin{abstract}
This paper looks briefly at aspects of iron loss assessment in switched reluctance machines and addresses issues that can arise when attempting to measure the flux linkage/current loops and the magnetizing curves experimentally.
\end{abstract}

Index Terms-Switched reluctance motors, iron loss, current flux linkage loops

\section{INTRODUCTION}

$\mathrm{C}$ ORE losses are usually calculated using the Steinmetz equation, however in switched reluctance machines (SRMs) the flux waveforms are non-sinusoidal and different parts of the magnetic circuit have different flux waveforms. Several methods to evaluate the core losses in SRM have been previously described by several authors including Hayashi [1], Materu [2] and Liou [3]. This paper will look at typical predicted losses in an SRM using the SPEED software, which uses a modified Steinmetz equation. Then it will then address the problems by looking at measured current/flux linkage curves and also the magnetizing curves.

\section{PREDICTED LOSSES IN AN SRM USING SPEED SOFTWARE}

An 8/6 SRM (Fig. 1 and Table I) was used to assess the core losses and the package PC-SRD from the SPEED Laboratory, University of Glasgow, was used to calculate the core losses (from analytic magnetic circuits) under similar performance parameters for different core materials (6 different steels were simulated). The machine had an original winding which was damaged; it was rewound by hand with a winding with fewer turns but slightly thicker wire. This brought down the voltage rating. The main control parameters for the simulations are presented in Table II. In addition to the voltage de-rating, the speed was reduced because of the speed rating of the load. From the results obtained (Table III), it can be clearly observed that the core losses vary considerably depending on the core material of the motor, and this is an important area for the study since it affects the efficiency (varying from $41.3 \%$ to $73.2 \%)$. The experimental machine has an M19 29 gage material and the machine is operating with a current density of

The authors are with the Department of Electronics and Electrical Engineering, University of Glasgow, Glasgow, G12 8LT, UK, (corresponding author: phone +_44-141-3302768, fax +44-141-3303158, email d.dorrell@elec.gla.ac.uk).
$4 \mathrm{~A} / \mathrm{mm}^{2}$ which suggests that it is not at maximum current and far from fully loaded. However the torque was measured as $0.54 \mathrm{Nm}$ compared to $0.7 \mathrm{Nm}$ simulated. The difference will be addressed in the following sections.

TABLE I

MOTOR SPECIFICATION

\begin{tabular}{lc}
\hline \hline No. of phases & 4 \\
No. of stator/rotor poles & $8 / 6$ \\
Stator outer diameter [mm] & 120.7 \\
Stator slot-bottom diameter [mm] & 96.8 \\
Rotor outer diameter [mm] & 60.0 \\
Rotor slot-bottom diameter [mm] & 43.2 \\
Air gap [mm] & 0.3 \\
Shaft diameter [mm] & 25.4 \\
Stack length [mm] & 75 \\
Stator pole arc & $22.6^{\circ}$ \\
Rotor pole arc & $23^{\circ}$ \\
Turns per coil & 38 \\
Resistance @ 20 ${ }^{\circ} \mathrm{C}$ & $0.3 \Omega$ \\
Minimum inductance [mH] & 1.45 \\
Maximum inductance [mH] & 9.15 \\
Rated voltage of original machine [V] & 270 \\
Rated speed of original machine [rpm] & 5000 \\
\hline \hline
\end{tabular}

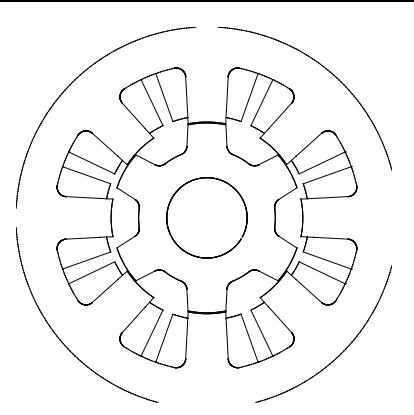

Fig. 1. Cross section of 8/6 Pole Switched Reluctance motor

TABLE II

MOTOR CONTROL PARAMETERS

\begin{tabular}{ll}
\hline \hline Speed & $1500 \mathrm{rpm}$ \\
DC Voltage & $80 \mathrm{~V}$ \\
Current limit & $7 \mathrm{~A}$ \\
Current Hysterisis band & $0.2 \mathrm{~A}$ \\
Turn-on angle Th0 & $35^{\circ}$ \\
Turn-off angle ThC & $55^{\circ}$ \\
\hline \hline
\end{tabular}

\section{Aligned MAGnetizING CURVES}

Fig. 2 shows the magnetizing curves for the experimental machine when the rotor is aligned. It might be expected that the high voltage loop would enclose the larger area (due to eddy current loss) but this was found not to be the case. 
However, the flux density is slightly higher in the low voltage case. The period for the loop in the high voltage case was $2 \mathrm{~ms}$ and for the low voltage case it was $15 \mathrm{~ms}$. The aligned magnetizing curve calculated from SPEED is also included and it can be observed that the agreement is good for the high voltage case and reasonable for the low voltage case.

TABLE III

SPEED CALCULATED LOSSES WITH DIFFERENT MATERIALS AT 1500 RPM

\begin{tabular}{lccccc}
\hline \hline MATERIAL & $\begin{array}{c}\text { CORE } \\
\text { LOSSES } \\
(\mathrm{W})\end{array}$ & $\begin{array}{c}\text { TOTAL } \\
\text { LOSSES } \\
\text { (Inc mech } \\
\text { loss) }(\mathrm{W})\end{array}$ & $\begin{array}{c}\text { IRON LOSS AS } \\
\text { PROPORTION } \\
\text { OF TOTAL } \\
\text { LOSS }(\%)\end{array}$ & $\begin{array}{c}\text { TRQUE } \\
(\mathrm{Nm})\end{array}$ & $\begin{array}{c}\text { EFFNCY } \\
(\%)\end{array}$ \\
M19 29 gage & & & & & \\
(actual) & 11.0 & 40.1 & 27.4 & 0.70 & 73.2 \\
M19 24 gage & 21.9 & 51.0 & 42.9 & 0.63 & 65.9 \\
M19 3\% Si & 14.0 & 43.0 & 32.5 & 0.67 & 71.0 \\
Losil 800 / 65 & 56.0 & 85.1 & 65.8 & 0.38 & 41.3 \\
Losil 500 / 65 & 28.3 & 57.2 & 49.5 & 0.57 & 60.8 \\
Transil Bs 35 & 13.5 & 42.4 & 31.8 & 0.66 & 71.1 \\
\hline \hline
\end{tabular}

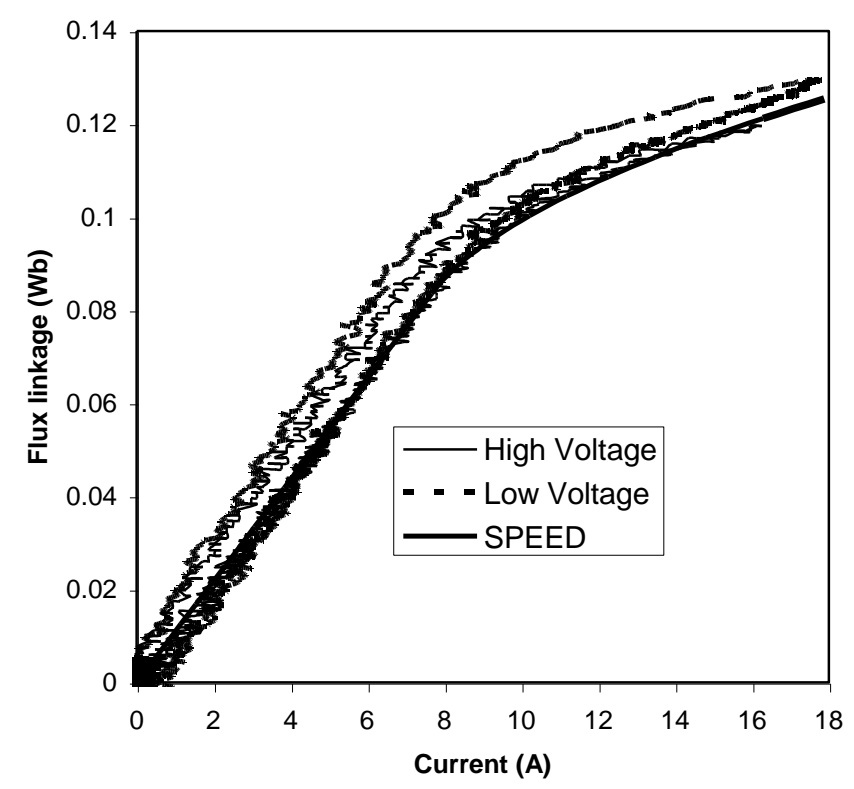

Fig. 2. Magnetizing curves at high voltage $(120 \mathrm{~V})$ and low voltage (20 V).

\section{Measured Flux LinKage/CuRRENT LoOP}

The current/flux linkage curves cannot be obtained directly and it requires the integration of the voltage signal to derive them. The flux linkage can be obtained by integration of a search coil voltage but to get the actual flux linkage curve, the voltage across the actual coils should be measured and the voltage drop across the coil resistance subtracted. This requires accurate resistance measurement and any thermal change in resistance to be incorporated. The incremental change in flux linkage is given by

$$
\Delta \Phi_{n}(t)=\left(v_{n}(t)-i_{n}(t) R\right) \Delta t
$$

where $\Delta t$ is the step period. As well as careful measurement of phase resistance care should be taken to ensure that there is no voltage or current offset. The flux is then given by

$$
\Phi_{n}(t)=\sum_{1}^{n} \Delta \Phi_{n}(t)
$$

Fig. 3 gives the flux linkage loops for one phase over a period of $50 \mathrm{~ms}$. Since for a speed of $1500 \mathrm{rpm}$ this represents a period of 1.25 revolutions, i.e, 7.5 strokes per phase (7 complete strokes). The voltage and current waveforms from the digital storage scope are unprocessed and unfiltered. There are 2000 samples, thus the sample time is $0.025 \mathrm{~ms}$.

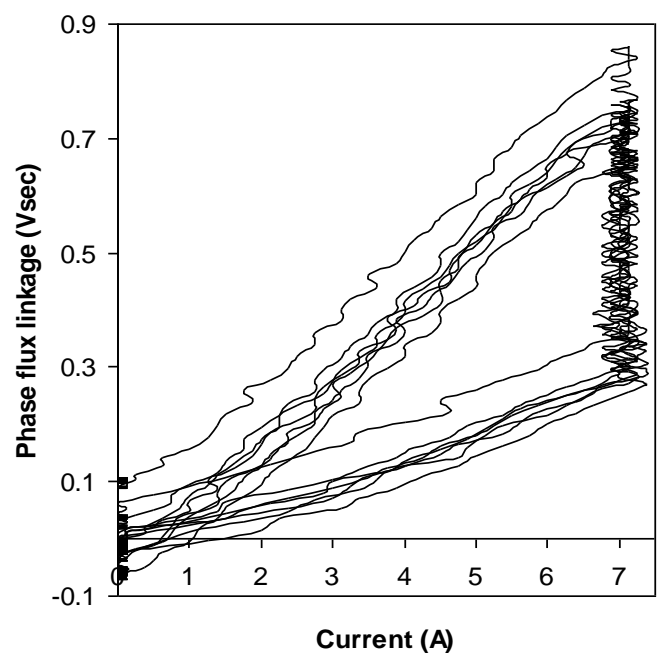

Fig. 3. Flux linkage/current loops when the firing angles are $\mathrm{Th} 0=35^{\circ}$ and $\mathrm{ThC}=55^{\circ}$

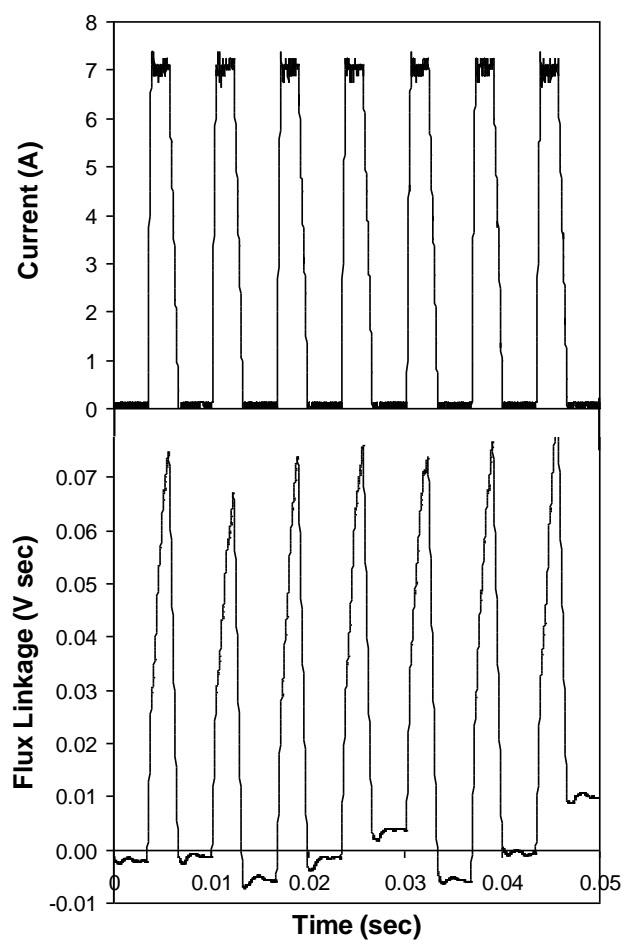

Fig. 4. Phase current (top) and flux linkage (bottom) when the firing angles are $\mathrm{Th} 0=35^{\circ}$ and $\mathrm{ThC}=55^{\circ}$

The flux linkage and current waveforms are shown in Fig. 4. It can be seen that there is a variation of flux linkage over the seven cycles; this can also be observed in Fig. 3. It is difficult to assess whether this is numerical error or switching error without comparison to a search coil voltage, however it is 
anticipated that the total energy conversion can be obtained by calculating the total area enclosed in all the loops across all four phases; this gives the total energy conversion and iron loss over the $50 \mathrm{~ms}$ period. An average can also be taken to obtain an average loop. The actual voltage across the phase is shown in Fig. 5; obviously this is supplied by a PWM bridge converter and since the voltage is being sampled then a variance (aliasing) between successive voltage cycles due to the phasing between the PWM switching and the sampling frequency is possible.

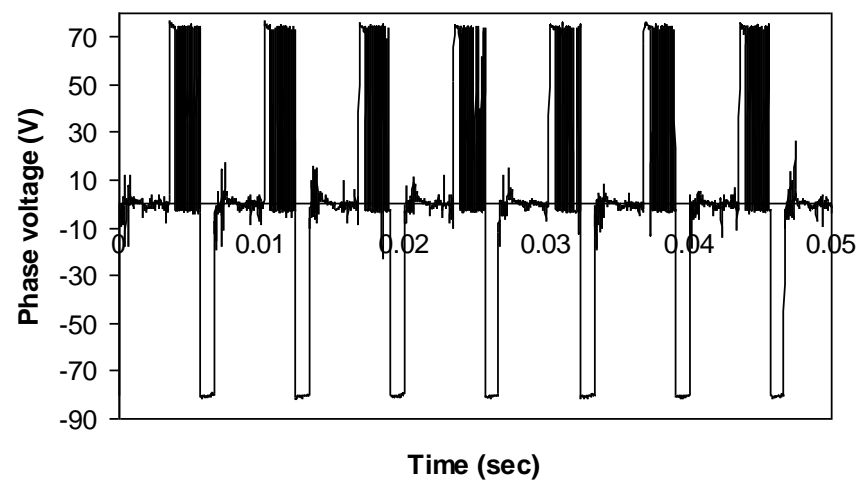

Fig. 5. Phase voltage when the firing angles are $\mathrm{Th} 0=35^{\circ}$ and $\mathrm{ThC}=55^{\circ}$

\section{ASSESSMENT OF IRON LOSS FROM EXPERIMENTAL RESULTS}

The iron loss can be assessed by consideration of the area of the flux linkage loops. This represents the electromechanical energy conversion and the iron loss. The electromechanical energy conversion is split between the shaft torque and the friction and windage loss. The latter can be determined by measuring the torque when the motor is turned unexcited at $1500 \mathrm{rpm}$. This gave a torque of $0.068 \mathrm{Nm}$ which is a $10.5 \mathrm{~W}$ loss. The area enclosed by all flux linkage loops for all four phases can be obtained from the equation:

$$
E_{\text {Loop }}=\sum_{P h=1}^{4} \sum_{n=2}^{N}\left\{\frac{\left(\Phi_{n}^{P h}(t)+\Phi_{n-1}^{P h}(t)\right)}{2}\left(i_{n-1}^{P h}(t)-i_{n}^{P h}(t)\right)\right\}
$$

so that the iron loss is

$$
P_{\mathrm{Fe}}=\frac{E_{\text {Loop }}}{\text { Measured period }}-T_{\text {measured }} \omega_{r}-P_{\text {Friction+Windage }}
$$

The input power could be obtained using a power analyzer, however, to check for consistency, the power can also be obtained from the voltage and current by multiplying them together to get the instantaneous power, then averaging over the measured period. Similarly the copper loss can be obtained from the measured current and resistance. Table IV shows power and loss components from the measurements for each phase and compares the results obtained from the measured values to the results from the SPEED simulation. The predicted iron loss from the modified Steinmetz equation seems reasonable (given the experimental error observed in the measurements) however there appears to be an overestimate of the torque due to a large flux linkage loop. Therefore Fig. 6 compares the average measured flux linkage loop to the simulation. Clearly the divergence appears to be during turnon where the simulation predicts a faster response.

TABLE IV

POWER AND LOSS COMPONENTS PER PHASE (MEASURED)

\begin{tabular}{lcccccc}
\hline \multicolumn{1}{c}{ PHASE } & 1 & 2 & 3 & 4 & Total & SPEED \\
$\mathrm{P}_{\text {in }}$ & 30.1 & 31.9 & 34.1 & 31.5 & 127.6 & 149.7 \\
$\mathrm{P}_{\mathrm{cu}}$ & 4.7 & 4.3 & 4.3 & 3.8 & 17.1 & 18.6 \\
$\mathrm{P}_{\text {in }}-\mathrm{P}_{\mathrm{cu}}$ & 25.4 & 27.6 & 29.8 & 27.7 & 110.5 & 131.1 \\
$\mathrm{P}_{\text {Loop }}$ & 25.5 & 27.5 & 28.9 & 27.4 & 109.3 & 131.1 \\
$\mathrm{P}_{\mathrm{F}+\mathrm{W}}$ & --- & --- & --- & --- & 10.5 & 10.5 \\
$\mathrm{P}_{\text {Torque }}$ & --- & --- & --- & --- & 84.8 & 109.6 \\
Calc PFE & --- & --- & --- & --- & 14.0 & 11.0 \\
\hline \hline
\end{tabular}

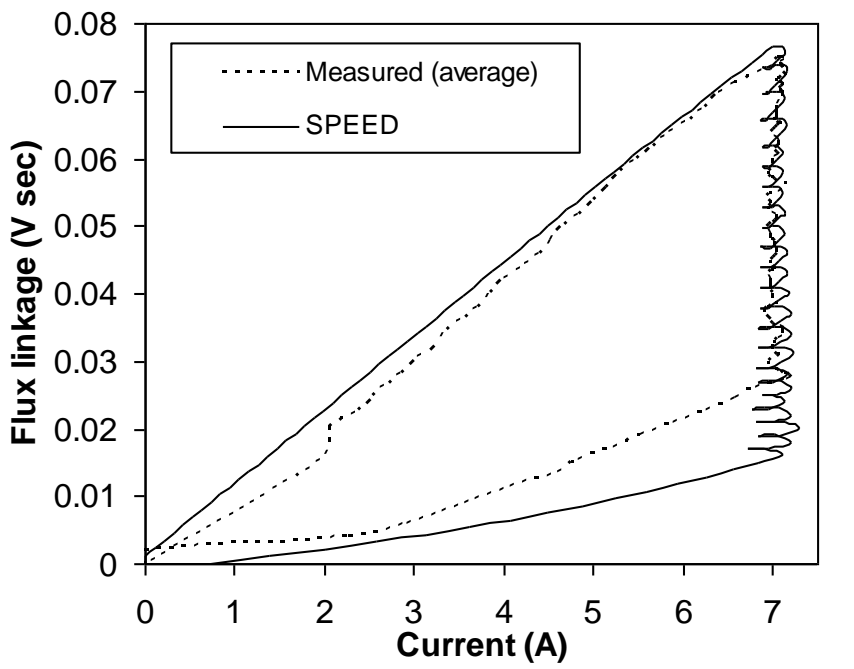

Fig. 6. Comparison between mean-measured and SPEED-calculated flux linkage loops at $\mathrm{Th} 0=35^{\circ}$ and $\mathrm{ThC}=55$

\section{CONCLUSION}

This paper illustrates that iron loss can affect the performance of a switched reluctance machine and details a method for measuring the iron loss. The paper also validates the SPEED design software and highlights the importance of obtaining good magnetizing curves in order to obtain accurate torque calculations.

\section{ACKNOWLEDGMENT}

The work was carried out while Mr Chindurza was a research student with the SPEED Laboratory, University of Glasgow and he acknowledges the financial support from the Laboratory during this period.

\section{REFERENCES}

[1] Y. Hayashi and T. J. E. Miller, "A New Approach to Calculating Core Losses in the SRM", IEEE Transactions on Industry Applications, Vol 31, No 5, September 1995.

[2] P. N. Materu and R. Krishnnan, "Estimation of Switched Reluctance Motor Losses", IEEE Transactions on Industry Applications, Vol 28, No 3, May 1992.

[3] S. P. Liou and J. Ye, "'Flux Distribution and Core Losses of Switched Reluctance Motors", IEEE Conference 1996. 